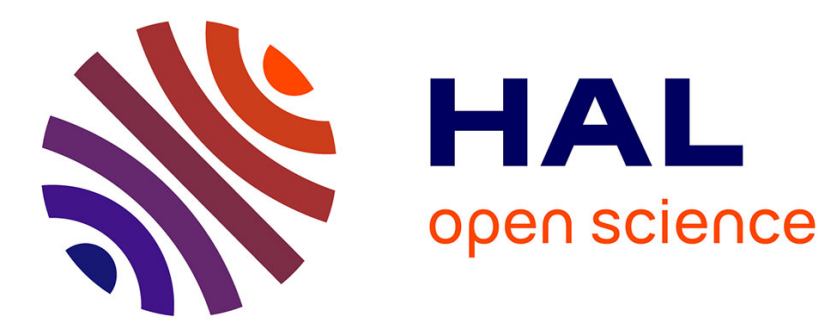

\title{
Multiple Scattering Calculation of Absorption Spectrum and Diffraction Calculation: Application to Nanometer Scale Copper Metallic Particle
}

\author{
Dominique Bazin, A. Bensaddik, V. Briois, Ph. Sainctavit
}

\section{To cite this version:}

Dominique Bazin, A. Bensaddik, V. Briois, Ph. Sainctavit. Multiple Scattering Calculation of Absorption Spectrum and Diffraction Calculation: Application to Nanometer Scale Copper Metallic Particle. Journal de Physique IV Proceedings, 1996, 06 (C4), pp.C4-481-C4-485. 10.1051/jp4:1996445 . jpa00254328

\section{HAL Id: jpa-00254328 \\ https://hal.science/jpa-00254328}

Submitted on 1 Jan 1996

HAL is a multi-disciplinary open access archive for the deposit and dissemination of scientific research documents, whether they are published or not. The documents may come from teaching and research institutions in France or abroad, or from public or private research centers.
L'archive ouverte pluridisciplinaire HAL, est destinée au dépôt et à la diffusion de documents scientifiques de niveau recherche, publiés ou non, émanant des établissements d'enseignement et de recherche français ou étrangers, des laboratoires publics ou privés. 


\title{
Multiple Scattering Calculation of Absorption Spectrum and Diffraction Calculation: Application to Nanometer Scale Copper Metallic Particle
}

\author{
D. Bazin*, A. Bensaddik*, V. Briois* and Ph. Sainctavit*,** \\ *.LURE, Bât. 209D, Université de Paris-Sud, 91405 Orsay cedex, France \\ ** LMCP UR09, Universités Paris VI et Paris VII, 75252 Paris cedex 05, France
}

\begin{abstract}
Résumé : Jusqu'à présent, seule la partie EXAFS (Extended x-ray absorption fine structure) du spectre d'absorption $\mathrm{X}$ i.e. celle comprise entre $40 . \mathrm{eV}$ et $1000 . \mathrm{eV}$ après seuil était simulée. L'avènement de codes de calculs performants tenant compte des processus de diffusion multiple du photoelectron nous permet désormais une simulation fiable du seuil d'absorption (XANES : $\mathrm{X}$-ray absorption near edge structure). Dans le domaine des agrégats métalliques nanométriques supportés, nous comparons les résultats obtenus avec deux codes de calculs FEFF6 écrit par $\mathbf{J}$. RHER et CONTINUUM écrit par NATOLI et montrons la complémentarité existant entre la spectroscopie d'absorption X et la diffraction aux grands angles (WAXS : Wide Angle X-ray Scattering)
\end{abstract}

\begin{abstract}
XAFS spectroscopy is a very efficient tool to describe local organisation and to determine the size and the lattice of nanometric metallic particles which are major information regarding their electronic properties. Nevertheless, good accuracy is hard to obtain. In order to evaluate the sensitivity of XANES (X-ray Absorption Near Edge Structure) and WAXS (Wide Angle X-ray Scattering) techniques versus these structural parameters, different multiple scattering (M.S.) calculations using either the NATOLI's code or the REHR's code have been performed for very small metallic clusters of copper.
\end{abstract}

\section{INTRODUCTION}

Among the different characterisation techniques, those related to synchrotron radiation are able to determine both the size and the lattice of nanometer scale metaliic particles even for material under extreme conditions such as high temperature, high pressure or exotic gas environment. In this work, we compare the sensitivity of these different techniques : EXAFS (Extended X-ray Absorption Fine Structure), XANES (X-ray Absorption Near Edge Structure) and WAXS (Wide Angle X-ray Scattering) to the size and the lattice of metallic copper clusters. In the Exafs part of the spectrum, only single scattering process of the photoelectron occurs. For the XANES part, the $\mathrm{K}$ absorption spectrum of most elements of the periodic table can be only simulated by the means of multiple scattering (M.S.) of the photoelectron on the atoms. S. framework. Full M. S. calculations can be performed by using the CONTINUUM code developed by NATOLI and co-workers [1]. Recently REHR and co-workers [2] have proposed the FEFF 6 code based on the development of the scattering series. Both codes have been used for clusters in Oh symmetry with 13 and 55 atoms (cubooctahedra). The purpose of this paper is twofold. First, it is interesting to compare both codes where the same physics is at the root with two different mathematical expression. Second, by a comparison of EXAFS, XANES and WAXS techniques, we hope to determine which technique is the best to estimate the size and the lattice of small clusters. Regarding the size, EXAFS spectroscopy is one of the most powerful technique. We have already discuss the different aspects of this major problem. The error made on the measure of the cluster size is rather important $[3,4]$ and has to be handled with care. 


\section{THE XANES PART OF SMALL METALLIC COPPER PARTICLES}

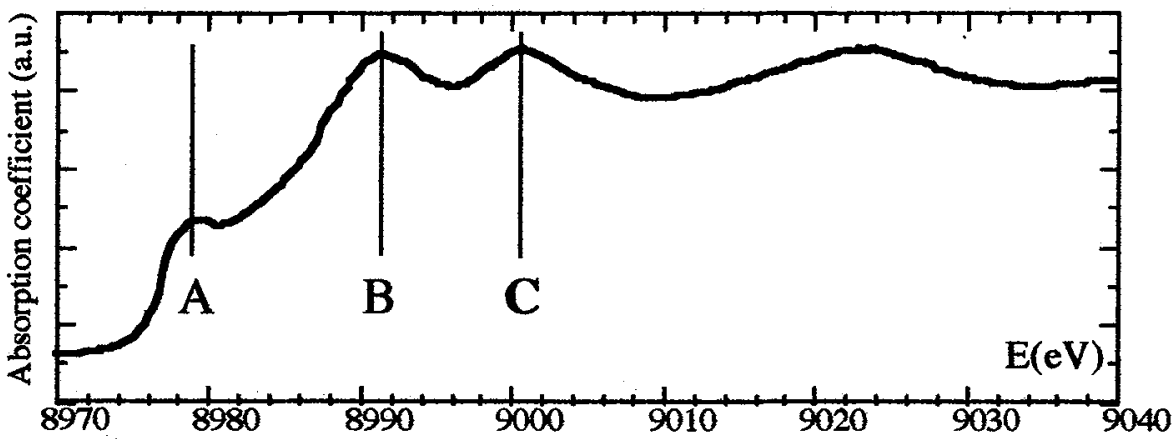

Figure 1 : XANES spectrum of the copper foil

Figure 1 : Spectre d’absorption d'une fetrille de cuivre

Numerous works deal with the simulation of the XANES spectrum (Figure 1) of the copper foil $[6,7]$ which exhibits three main features $A$ (transition $1 s$ to $4 p$ in the $3 d^{10}$ configuration), $B$ and C. This FCC lattice is generally reproduced in the multiple scattering framework in the muffintin approximation by using large clusters of few hundreds of atoms in which absorbing atom is always at the centre of the cluster. It is considered that the surface atom contribution to the total cross section is negligible. For nanometer scale clusters, the symmetry of translation is lost and atoms are not equivalent ; the surface atoms contribute to the photoabsorption cross section and therefore it is necessary to consider each kind of absorbing atoms separately. In a 13 atom cluster (respectively 55 atoms) there are two non equivalent sites (respectively five sites). Calculated XANES spectra of nanometer metallic particles are obtained after averaging the contribution of each type of atom.

\subsection{Full multiple scattering approach : the CONTINUUM program.}

The potentials of the initial and final states are obtained by the superposition of a molecular Coulomb potential with an $\mathrm{X} \alpha$ exchange potential. The electronic configuration of the final state $(Z+1)$ is $1 s^{1} 2 s^{2} 2 p^{6} 3 s^{2} 3 p^{6} 3 d^{10}$ mimicking the "relaxed and screened" final potential. In order to avoid shift of the calculated structures due to a change of the interstitial potential values, we have fixed the interstitial potential for all the different calculations. It is equal to its value when the absorbing atom is located at the centre.

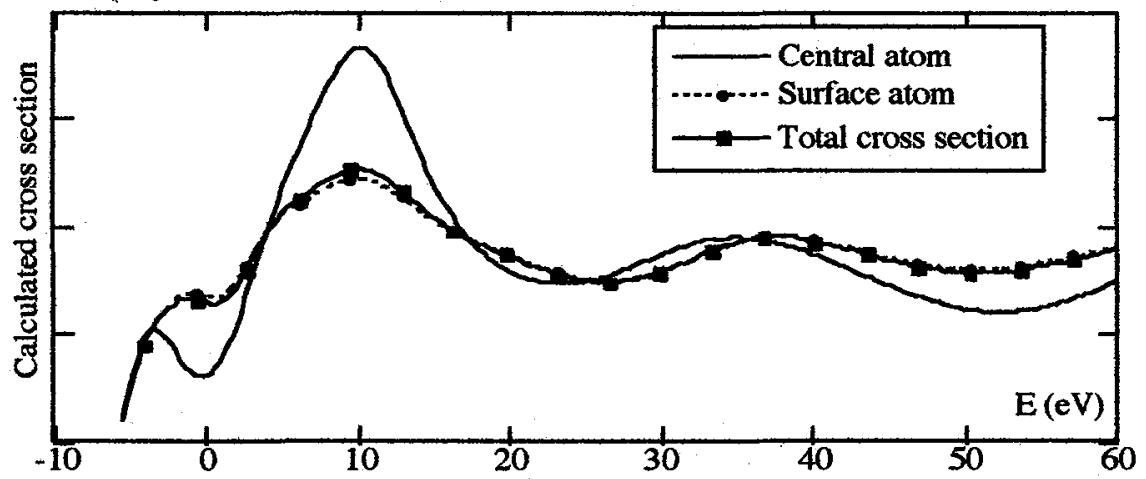

Figure 2 : Total calculated cross section using CONTINUUM code for the $13 \mathrm{Cu}$ atom cluster compared with those obtained for surface and central atoms only.

Figure 2 : Sections efficaces calcules avec le programme CONTINUUM pour un agrégat de 13 atomes de cuivre. Sont représentéces également la contribution de l'atome central et celles des atomes de surface. 
Figures 2. and 3. show the calculated cross sections for clusters of 13 and 55 atoms, respectively. It is essential to consider each kind of atom inside the cluster as the signal coming from the surface and the central atom are definitely not the same. 13 and 55 atom clusters are much different. The 13 atom cluster spectrum is essentially due to surface atoms contribution while the 55 atom cluster spectrum is essentially due to the $(1,1 / 2,1 / 2)$ type atoms. Even for a small 13 cluster atom cluster the feature $A$ is already present giving a good evidence of the metallic state.

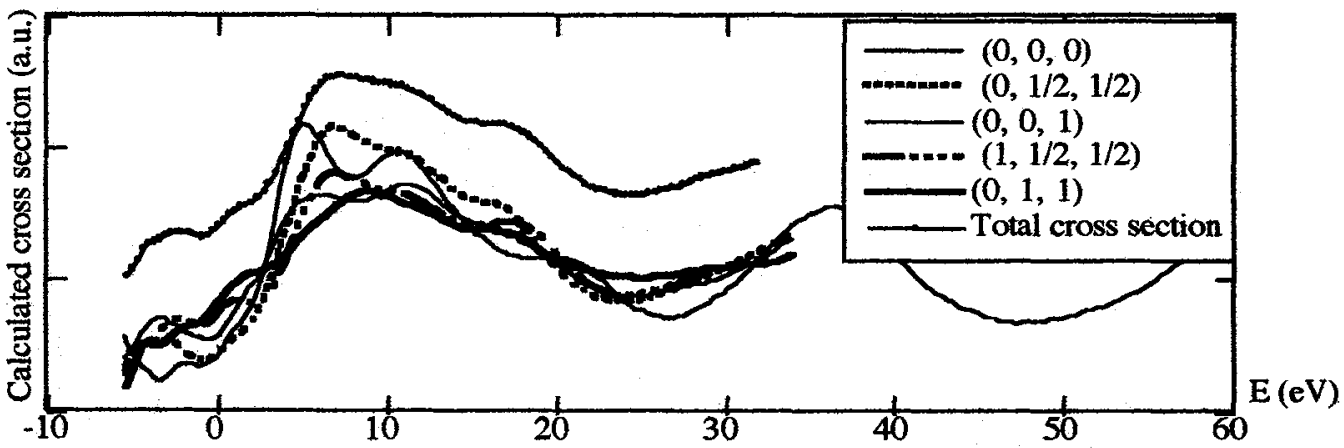

Figure 3 : Total calculated cross section using CONTINUUM code for the $55 \mathrm{Cu}$ atom cluster compared with those obtained for each kind of absorbing atoms. For clarity, the total cross section has been shifted .

Figure 3 : Sections efficaces calculées avec le programme CONTINUUM pour un agrégat de 55 atomes de cuivre. La contriburion de chaque type d'atomes a été calculée. Pour plus de clarté, la moyenme pondérée obtenue a été décalée.

\subsection{Multiple scattering series : the FEFF6 code}

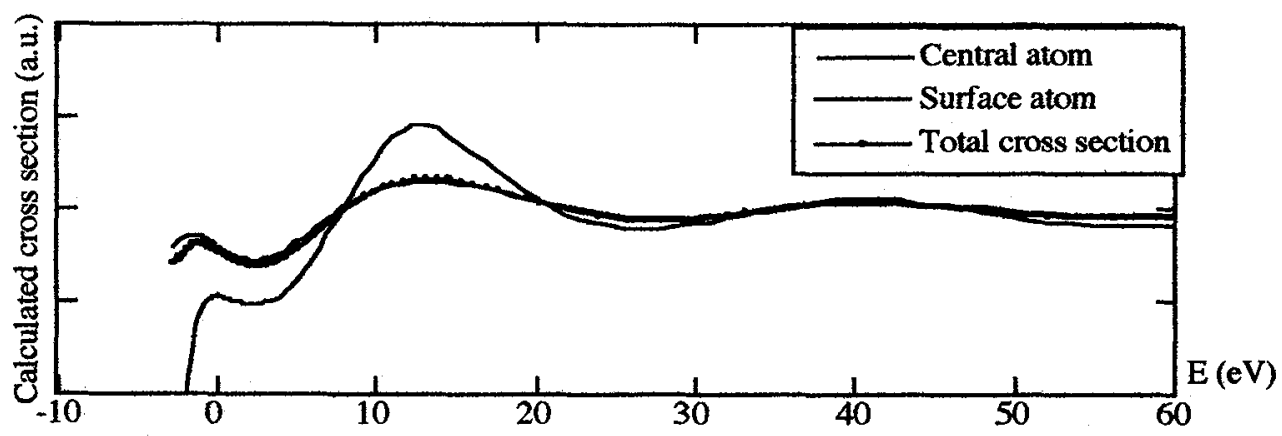

Figure 4 : Total calculated cross section using the FEFF 6 code for the $13 \mathrm{Cu}$ atom cluster compared with those obtained for surface and central atoms only.

Figure 4 : Sections efficaces calculées pour un agrégat de 13 atomes de cuivre en utilisant le code de calcul FEFF6. Sont représentés également la contribution de l'atome central et celles des atomes de surface.

We just recall here that this code consists of 4 modules (a scattering potential, a path, a scattering matrix, an XAFS). Among the different options note that an exchange card specifies the energy dependent exchange correlation potential to be used (HEDIN-LUNQVIST; DIRACHARA ). In our case, the HEDIN-LUNDQVIST self energy has been used (default card). 


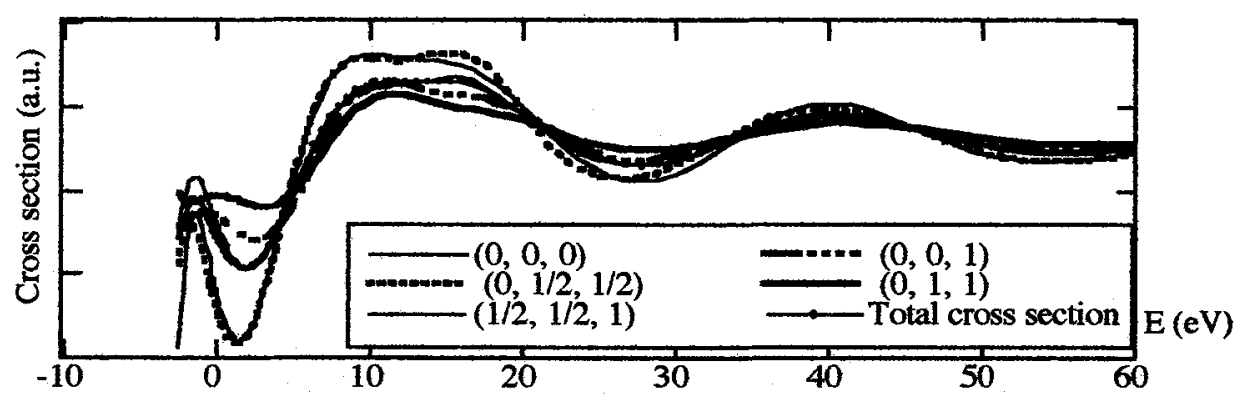

Figure 5 : Total calculated cross section using the Feff 6 code for the $55 \mathrm{Cu}$ atom cluster compared with those obtained for each kind of absorbing atoms.

Figare 5 : Differentes sections efficaces calculées (totale et partielle) grâce au code FeFF6 pour un agrégat de 55 atomes de crivre.

In this case, we calculate the XANES of two small clusters which contains respectively 13 and 55 atoms (Figure 4. and Figure 5.). Negative cross sections come from the neglect of atomic absorption. Nevertheless, the results obtained are in line with the preceding full M.S. calculations regarding the amplitude of the modulations related to the central and the surface atoms. Also, lifetime broadening is included contrary to our NATOLI's calculations. That is why features in the edge are sharper in the case of the NATOLI's code.

\section{DIFFRACTION SPECTRA OF METALLIC COPPER PARTICLES}

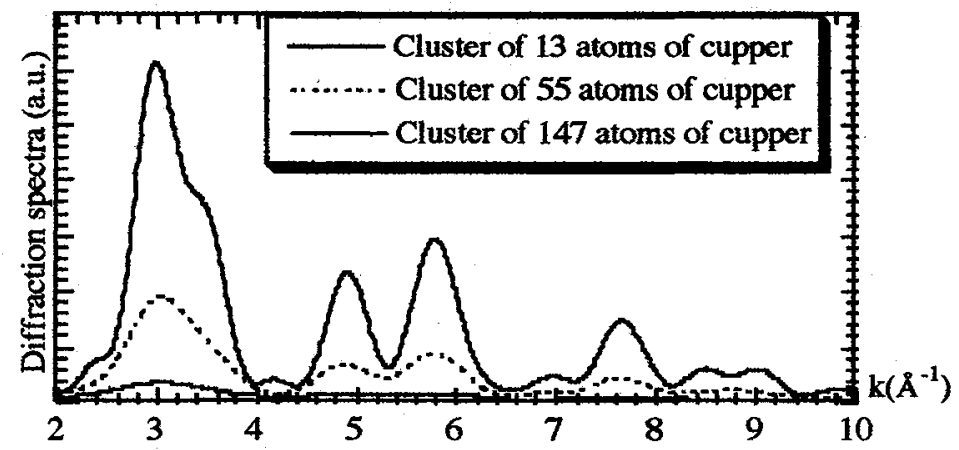

Figure 6 : Diffraction spectra of copper clusters containing 13,55 or 147 atoms with a FCC network.

Figure 6 : Spectres de diffraction calculés en utilisant la formule de Debye pour de petits agrégats contenant 13,55 et 147 atomes de ctrivre.

We have calculated the diffracted intensity for different copper clusters according to the DEBYE formulae [3,4]. For $f_{0}(k)$, we use the CROMER and MANN parameters [7]. Figure 6 shows the results of these simple calculations and as noticed previously, the SCHERRER formula which links the width of the peak $\beta$ to $\varepsilon$ the size of the cluster $(\beta=\lambda / \varepsilon \cos (\theta) \lambda$ is the wavelength and $\theta$ definite the diffraction peak) is useless to measure the size of such small clusters $[3,4]$ basically because the diffraction peaks are not enough defined. Nevertheless, the calculated diff raction intensities seem to show that the limit for an accurate determination of both size and network is obtained for clusters containing around twenty atoms.

\section{DISCUSSION}

Our major point that has to be underscored is that for a 55 atom cluster spectrum, all the features $A, B$ and $C$ of the copper foil $K$ edge are already present. This is consistent with the fact that the surface atoms have along one specific direction the copper crystal long range order 
and in line with previous work of G. N. GREAVES et al. [6]. This is clearly related to the fact that forward and backward scattering are dominant. Since the surface atoms have a non isotropic environment, features are present but with lower intensities than for the copper foil spectrum. Moreover a 13 atom environment is not enough to produce the resonance $C$, its presence or its absence is a clear fingerprint of the cluster size that allows to distinguish the smallest clusters. Such calculations have boen confirmed by experimental results in the case of copper cluster in solid Ar matrix [8] and more recently by a study of copper clusters implanted in AlN matrix [9].

As a conclusion, further calculations are required for larger cuboctahedron and different lattices like BCC or HCP. The correlation with AWAXS remains also to be more deeply addressed.

\section{References}

[1] NATOLI C. R., MISEMER D. K., DONIACH S., KUTZLER F. W., Phys. Rev. A 22, 1104 (1980).

[2] REHR J. J., ALBERS R. C. , Phys. Rev. B41, 8149 (1990).

[3] D. BAZIN, D. SAYERS, Jpn J. Appl. P., Vol. 32 (1993) Suppl. 32-2 p 249

[4] D. BAZIN, D. SAYERS, Jpn J. Appl. P., Vol. 32 (1993) Suppl. 32-2 p 252.

[5] CROMER D. T. , MANN J. B., Acta Crys. A21, 321 (1968).

[6] GREA VES G. N., DURHAM P. J., DIAKUN G., QUINN P. , Nature 294,139 (1981).

[7] KITAMURA M., MURAMATSU S., SUGIURA C. , Phys. Rev. B, V33 , N8, 5294 (1986).

[8] MONTANO P. A., ZHAO J., RAMNATHAN M., SHENOY G. K., SCHULZE W., Z. Phys. D12,103 (1986).

[9] BOTOWSKI M., thesis of the University of Paris-Sud N ${ }^{\circ} 3801$, (1995). 